\title{
Cataract: Effect of designed nursing guidelines on patients to minimize postoperative complications
}

\author{
Neama Ahmed Mohamed, Mohamed Saad Abdel Rahman, Attyiat Hassan Hussein \\ Head nurse in Ophthalmic Department at Assiut University Hospital Egypt. \\ Professor of Ophthalmology Ophthalmic Department Faculty of Medicine Assiut University Egypt. \\ Lecturer of Medical surgical Nursing Adult Nursing Department Faculty of Nursing Assiut University Egypt.
}

\begin{abstract}
Cataract is the opacification of the normally clear lens of the eye. Aim: to determine the educational needs of patients with cataract, to design nursing guidelines and to evaluate the effect of designed nursing guidelines on patient outcomes. Subjects and methods: the study was conducted in the ophthalmic department at Assiut university hospital. Study design: Quasi-experimental research design was utilized in this study. Tools: three tools was used, tool one patient with cataract assessment, it was divided into two parts concerning: patients` sociodemographic data, assessment patient's knowledge, tool two designed nursing guidelines, tool three post operative complications for assessment patients with cataract observation checklist. Results: the majority of both the study and control groups $(60.0 \%$ and $66.7 \%)$ were female, $(73.4 \%, 33.3 \%)$ were illiterate, $(56.7 \%$ and $63.3 \%)$ were house wife, $(43.3 \%, 60.0 \%)$ their ages were between $41-60$ years of age, The results also revealed that, there was significant statistical difference between pre and post application of guidelines for the study group

Conclusions: knowledge level of the study group patients after application of nursing guidelines was higher than knowledge level of control group. Recommendation: Providing a written instruction booklet is of great important for the patients before discharge to minimize postoperative complications.
\end{abstract}

\section{Key word: Cataract, Guidelines \& Nursing.}

\section{Introduction}

Cataract is the commonest causes of visual impairment and blindness worldwide. A cataract is defined as opacity within the crystalline lens. The patient may have a cataract in one or both eyes. If cataracts are present in both eyes, one may affect the patient's vision more than the other. Lewis et al, (2013) there are several causes of cataract formation. Aging is the most common causes, diabetes mellitus, hyperparathyroidism, local inflammation, long- term medication such as steroids and thyroxin, radiation especially if the patient is undergoing treatment for malignancy of the head and neck. Pudner, (2010) Signs and symptoms of cataract include cloudy or blurred vision, decreased visual acuity, increased glare, and poor night vision. Diagnosis is made by a history of progressive decrease in vision and by the ophthalmic examination. Muma \& Lyons, (2011) When cataracts interfere with daily living and quality of life, treatment is recommended. The only treatment for cataracts is surgical removal of the cloudy lens. Intraocular lenses which come in various types are typically inserted after lens removal. Eye glasses or contact lenses are needed if no lens is reinserted. Eye glasses may also be needed with some of the lens implants. Williams \& Hopper, (2012)

There are different surgical techniques used in cataract surgery includes, Phacoemulsification (PHACO) is also called "small incision cataract surgery", and is an advanced form of extra capsular cataract surgery which the most common technique used by developed countries. Most cataract removals today are done by phacoemulsification and is the most frequently used method with cataract in the adult patient. Rosalin et al., (2013)

Under local anaesthetic a surgeon performing phacoemulsification makes a small opening on the side of the cornea. A device that sends ultrasound vibrations is inserted into the eye and breaks the lens into small pieces. The fragments are then removed by suction through the small incision in the eye. After the cataract is removed, the surgeon usually replaces it with a new, manmade lens called an intraocular lens or IOL. This procedure is called "intraocular lens implantation". Soosan et al., (2012)

Extracapsular cataract extraction (ECCE): Extracapsular cataract extraction involves the removal of almost the entire natural lens while the elastic lens capsule (posterior capsule) is left intact to allow implantation of an intraocular lens. It involves manual expression of the nucleus through a large (usually $10-12 \mathrm{~mm}$ ) incision made in the cornea or sclera. Although it requires a larger incision and the use of stitches, the conventional method may be indicated for patients with very hard cataracts or other situations in which phacoemulsification is problematic. Keithet et al., (2009) Intracapsular 
cataract extraction (I CCE) involves removal of the lens and surrounding lens capsule in one piece. After cataract removal of the lens, an artificial plastic lens is implanted. Anil, (2013)

The major early and late complications of cataract surgery are endophthalmitis, wound leak, retained lens fragments, loss of vitreous, retinal detachment, dislocations of the intraocular lens, corneal edema, elevated intraocular pressure, chronic inflammation, cystic macula edema, and posterior capsule pacification. stannard \& Krenzischek, ( 2012)The role of the nurse in pre-operative and postoperative includes, assessing, planning, and implementing measure necessary to ensure safe and effective care. Health education for patient and family, about eye care, medications, follow-up visit schedule, signs and symptoms of possible complications.

Watkison, (2009)

\section{Significance of the study}

In Egypt main cause for blindness is cataract. Approximately 961 patients with cataract were reported in ophthalmic department at Assiut University Hospital through 2014 and average 53 patients with cataract has been operated monthly. Those patients are in need for nursing guidelines to minimize their postoperative complications.

\section{Aims of the study}

The aim of the study were to determined the educational needs of patients with cataract, to design nursing guidelines, and to evaluate the effect of designed nursing guidelines on patients outcomes.

\section{Subjects and Methods}

Research design: Quasi-experimental research design was utilized in this study.

Research hypotheses: To fulfill the aims of the study, the following research hypothesis were formulated:

$>$ Studied patient post operative attending nursing guidelines exhibit higher knowledge scores than control ones.

$>$ Studied patient implementing post operative nursing guidelines exhibit low minimal complications than control ones.

\section{I-Technical design}

Setting of the study: The study was conducted in the ophthalmic department at Assiut University hospital.

\section{Subjects}

A convenience sample of (60) adult patient from both sex their age ranged from (18-65) year. The patients were admitted at ophthalmic department for cataract surgery and divided to equal two groups (study and control group) 30 for each.

Tools: It was used three tools for data collection for this study.

Tool I: Patient with cataract assessment: It was designed by researcher after reviewing of national and international literature it consists of two parts:

Part (1): Socio-demographic and medical data: it includes age, gender, level of education, and occupation. Medical data included, duration of cataract, previous eye surgery, and risk factors (chronic disease, smoking, and family history).

Part (2): Assessment patient's knowledge sheet: to assess patients knowledge regarding cataract includes definition of cataract, causes, signs \& symptoms, complications, pre and post operative nursing care and patient instructions before discharge.( It included 39 items).

\section{Scoring system}

Each right answer was given 2 degree the total scores were 78 . Those who obtained less than $(50 \%)$ were considered having poor level of knowledge. (50\%) and more were considered having good level of knowledge.

Tool II: Designed nursing guideline for patient with cataract post operatively

This tool was developed by the researcher based on patients assessment needs after reviewing current national and international literature to minimize post operative complications. It was formulate and introduced to the patients in the forms of sessions. The nursing guidelines booklet was revised and modified based on the expertise comments, it was written in Arabic using simple language with illustrations.

Tool III: Post operative complications for assessment patients with cataract observation checklist

It used to assess post operative complications of cataract surgery, includes, eye bruising, corneal edema, uveitis, endophtalmitis, dislocated intraocular lens, wound leak, intraocular hemorrhage, astigmatism, iris prolapse, raised intraocular pressure, ptosis, secondary glaucoma, hyphema, macular edema, retinal detachment and posterior capsule opacification.

\section{Operational design}

\section{The study was carried out on three phases} 1-Preparatory phase

This phase stared by:

A review of current and past, local and international related literature as textbooks, articles, journals, periodicals, and magazines was done, study tools were formulated, and this phase ended by contents validity and pilot study. 


\section{Content validity}

It was established by panel of 5 expertises who reviewed the instruments for clarity, relevance, comprehensiveness, understanding, applicability and easiness for administrative minor modifications were required. The content validity of this tool was checked by expert professors in fields of medicine and nursing and correction was carried out.

\section{Pilot study}

A pilot study was conducted on $10 \%$ (6 patients) of sample to evaluate the applicability and clarity, reliability feasibility of the tools, estimate the time needed for data collection, and test the feasibility of conducting the research after analyzing the pilot study result, minimal modifications were done accordingly. These patients were not included in the actual study.

\section{2- Implementation phase}

Data were collected during the period from 1/1/2014 to $1 / 8 / 2014$. At initial interview the researcher introduced herself to initiate line of communication in order to facilitate the implementation of the tools.

The researcher divided randomly the patients into both control group and study group and interview with each patient individually and explained the nature and purpose of the study.

The control group (patients who would not be expose to the designed nursing guidelines) was interviewed and assessed by using (tool 1 and tool III). The researcher filled out the patient assessment sheet (tool 1) to assess patients knowledge regard cataract preoperatively and filled out patient complications sheet (tool III) postoperative to assess post operative complications.

While study group exposed to the designed nursing guidelines, preoperatively then the researcher continued to give patients the guidelines during the post operative period until they were discharged. By using (tool 1) was done for all study group patients at the time of admission, and by using (tool III) was done to all study group post operatively before discharge and then after one month. The researcher explained to the patients designed nursing guidelines in the following sequence. The designed nursing guidelines were administered to the patient in two sessions the duration of each session was about (3045 minutes).

- The first session: The researcher started by introducing herself to the patient telling her/him about the aim of the meeting, orient patient regarding the designed guidelines. Contents of this session: Introduction, simple note on the anatomy of the eye, definition of cataract, causes, signs \& symptoms of the cataract. Treatment of cataract, and complications cataract surgery.

- The second session: summary about what has been discussed in a previous session, objective of the new session, contents of this session includes: preoperative care (day before operation and day of operation). Post operative care, immediately, routine care, instruction and health education about home care, follow-up after discharge from the hospital, signs and symptoms of complications, the patient must be return immediately to the hospital and some counseling to prevent infection.

Each patient in the study group obtained a copy of the designed nursing guidelines booklet.

\section{3-Evaluation phase}

1. Objective of tools scoring system.

2. Component of tool.

Evaluation phase was carried out through introducing (tool I and tool III) for all studied sample (both control and study group) the patients` knowledge has been evaluated by the researcher through filling the (tool I). As well as the researcher filled the Patient complications sheet using (tool III) during hospitalization and after one month post discharge after application of the designed nursing guidelines.

\section{III-Administrative design}

An official letter was issued from the Dean of faculty of nursing to head of Assuit University Hospitals and the head of the Ophthalmic Department .The researcher met ophthalmic surgeons' specialists for explaining the purpose of the study to gain their cooperation. In addition verbal consent was obtained from each participation patient to be included in the study.

\section{Ethical considerations}

1. Research proposal was approved from Ethical Committee in the faculty of nursing.

2. There is no risk for study subject during application of research.

3. Written consent was obtained from patients or guidance that are willing to participate in study, after explaining the nature and purpose the study.

4. Confidentiality and anonymity was assured.

5. Study subject have the right to refuse to participate and or withdraw from the study without any rational any time.

Study subject privacy will be considered during collection of data

\section{IV-Statistical design}

Data were collected and analyzed by computer program SPSS. Data expressed as mean, standard deviation, number and percentage. Tests for significance were applied, t-test, and one way ANOVA test, T-test is used to determine significant for numeric variable. Chi-square test is used to determine significant for non-parametric variable. A probability level of 0.05 was adopted as a level of significance for testing the research hypotheses. 


\section{Limitation of the study}

1- Level of Patient's education, some patients were illiterates resulting in a lack of assimilation of information and take long time to give nursing guidelines.
2- patient's anxiety and feeling of vulnerability may interfere with the ability to learn more information.

\section{Results}

Table (1): Distribution of studied sample (both control and study groups) as regarding to their sociodemographic characteristics.

\begin{tabular}{|c|c|c|c|c|c|}
\hline \multirow{2}{*}{ characteristics } & \multicolumn{2}{|c|}{ Control group $(n=30)$} & \multicolumn{2}{|c|}{ Study $\operatorname{group}(\mathrm{n}=\mathbf{3 0})$} & \multirow{2}{*}{$P$ value } \\
\hline & No. & $\%$ & No. & $\%$ & \\
\hline \multicolumn{5}{|l|}{ Age:(years) } & \multirow{5}{*}{0.305} \\
\hline $18-40$ & 3 & 10.0 & 9 & 30.0 & \\
\hline $41-60$ & 18 & 60.0 & 13 & 43.3 & \\
\hline $61-65$ & 9 & 30.0 & 8 & 26.7 & \\
\hline Mean \pm SD & \multicolumn{2}{|c|}{$46.6 \pm 1.4$} & \multicolumn{2}{|c|}{$46.6 \pm 1.4$} & \\
\hline \multicolumn{5}{|l|}{ Gender } & \multirow{3}{*}{0.372} \\
\hline Male & 10 & 33.3 & 12 & 40.0 & \\
\hline Female & 20 & 66.7 & 18 & 60.0 & \\
\hline \multicolumn{5}{|l|}{ Level of education } & \multirow{6}{*}{$0.056^{*}$} \\
\hline Illiterate & 10 & 33.3 & 22 & 73.4 & \\
\hline Read and write & 8 & 26.6 & 7 & 23.3 & \\
\hline Primary education & 5 & 16.8 & 1 & 3.3 & \\
\hline Secondary education & 5 & 16.8 & 0 & 0.0 & \\
\hline High education & 2 & 6.5 & 0 & 0.0 & \\
\hline \multicolumn{5}{|l|}{ Occupation } & \multirow{6}{*}{0.297} \\
\hline Employee & 1 & 3.3 & 0 & 0.0 & \\
\hline Farmer & 8 & 26.7 & 9 & 30.0 & \\
\hline Machinery work & 1 & 3.3 & 4 & 13.3 & \\
\hline House wife & 19 & 63.3 & 17 & 56.7 & \\
\hline Not work & 1 & 3.3 & 0 & 0.0 & \\
\hline
\end{tabular}

Independent sample T test

$*$ Statistical significant differences $(p<0.05)$

Table (2): Distribution of studied sample (both control and study groups) as regarding to their medical data.

\begin{tabular}{|c|c|c|c|c|c|}
\hline & \multicolumn{2}{|c|}{ Control group $(n=30)$} & \multicolumn{2}{|c|}{ Study $\operatorname{group}(n=30)$} & \multirow{2}{*}{$P$ value } \\
\hline & No. & $\%$ & No. & $\%$ & \\
\hline \multicolumn{5}{|l|}{ Duration of cataract } & \multirow{5}{*}{$0.021 *$} \\
\hline -One month & 3 & 10.0 & 8 & 26.7 & \\
\hline -Two months & 3 & 10.0 & 4 & 13.3 & \\
\hline -Three months & 5 & 16.7 & 4 & 13.3 & \\
\hline -More than three months & 19 & 63.3 & 14 & 46.7 & \\
\hline \multicolumn{5}{|l|}{ Previous eye surgery } & \multirow{3}{*}{0.125} \\
\hline -Yes & 12 & 40.0 & 9 & 30.0 & \\
\hline -No & 18 & 60.0 & 21 & 70.0 & \\
\hline \multicolumn{5}{|l|}{ Risk factors } & \multirow{3}{*}{$0.028 *$} \\
\hline -Yes & 9 & 30.0 & 16 & 53.3 & \\
\hline$-\mathrm{No}$ & 21 & 70.0 & 14 & 46.7 & \\
\hline \multicolumn{5}{|l|}{ Chronic diseases } & \multirow{4}{*}{0.175} \\
\hline -Diabetes mellitus & 3 & 10.0 & 12 & 40.0 & \\
\hline -Hypertension & 5 & 16.7 & 4 & 13.3 & \\
\hline -Cardiovascular disease & 1 & 3.3 & 0 & 0.0 & \\
\hline
\end{tabular}




\begin{tabular}{|c|c|c|c|c|c|}
\hline & \multicolumn{2}{|c|}{ Control group $(\mathbf{n}=30)$} & \multicolumn{2}{|c|}{ Study $\operatorname{group}(\mathbf{n}=30)$} & \multirow{2}{*}{$P$ value } \\
\hline & No. & $\%$ & No. & $\%$ & \\
\hline \multicolumn{5}{|c|}{ Smoking } & \multirow{3}{*}{0.162} \\
\hline -Yes & 6 & 20.0 & 8 & 26.7 & \\
\hline -No & 24 & 80.0 & 22 & 73.3 & \\
\hline \multicolumn{5}{|c|}{ Family history } & \multirow{3}{*}{$0.031 *$} \\
\hline -Yes & 4 & 13.3 & 11 & 36.7 & \\
\hline -No & 26 & 86.7 & 19 & 63.3 & \\
\hline
\end{tabular}

Independent sample T test

* Statistical significant differences $(p<0.05)$

Table (3): Distribution of Patients' knowledge (both control \& study groups) about cataract (pre \&post) application of nursing guidelines.

\begin{tabular}{|c|c|c|c|c|c|c|c|}
\hline \multirow{3}{*}{ Knowledge items } & \multirow{2}{*}{\multicolumn{2}{|c|}{$\begin{array}{c}\text { Control group }(\mathrm{n}=\mathbf{3 0}) \\
\text { Pre-guidelines }\end{array}$}} & \multicolumn{4}{|c|}{ Study group $(n=30)$} & \multirow{3}{*}{ P-value } \\
\hline & & & \multicolumn{2}{|c|}{ Pre-guidelines } & \multicolumn{2}{|c|}{ Post -guidelines } & \\
\hline & No. & $\%$ & No. & $\%$ & No. & $\%$ & \\
\hline Poor level & 23 & 76.7 & 26 & 86.6 & 4 & 13.4 & \multirow{3}{*}{$0.003 * *$} \\
\hline Good level & 7 & 23.3 & 4 & 13.4 & 26 & 86.6 & \\
\hline Mean \pm SD & \multicolumn{2}{|c|}{$1.3 \pm 0.2$} & \multicolumn{2}{|c|}{$1.5 \pm 0.3$} & \multicolumn{2}{|c|}{$22.3 \pm 2.3$} & \\
\hline
\end{tabular}

Table (4): Comparison between the control and study groups regarding to post operative complications of cataract surgery.

\begin{tabular}{|c|c|c|c|c|c|}
\hline \multirow{2}{*}{ Items } & \multicolumn{2}{|c|}{ Control group $(n=30)$} & \multicolumn{2}{|c|}{ Study $\operatorname{group}(\mathbf{n}=30)$} & \multirow{2}{*}{$P$ value } \\
\hline & No. & $\%$ & No. & $\%$ & \\
\hline 1. Eye bruising. & 1 & 3.3 & 1 & 3.3 & - \\
\hline 2. Corneal edema. & 3 & 10 & 2 & 6.6 & 0.121 \\
\hline 3. Endophtalmitis & 1 & 3.3 & 0 & 0.0 & 0.321 \\
\hline 4. Wound leak. & 1 & 3.3 & 0 & 0.0 & 0.321 \\
\hline 5. Raised intraocular pressure. & 4 & 13.3 & 3 & 10.0 & $0.012 *$ \\
\hline
\end{tabular}

* Statistical significant differences $(p \leq 0.05)$

Table (5): Relationship between patients' post operative complications and socio-demographic characteristics

\begin{tabular}{|c|c|c|c|c|}
\hline \multirow{3}{*}{ Items } & \multicolumn{4}{|c|}{$\begin{array}{c}\text { Post operative complications } \\
\end{array}$} \\
\hline & \multicolumn{2}{|c|}{ Control group $(\mathbf{n}=\mathbf{3 0})$} & \multicolumn{2}{|c|}{ Study group $(\mathrm{n}=30)$} \\
\hline & Mean \pm SD & P-value & Mean \pm SD & P-value \\
\hline \multicolumn{2}{|l|}{ Age } & \multirow{4}{*}{$0.042 *$} & & \multirow{4}{*}{$0.021 *$} \\
\hline $18-40$ & $0.5 \pm 0.4$ & & $1.4 \pm 0.3$ & \\
\hline $41-60$ & $1.2 \pm 0.3$ & & $1.4 \pm 0.2$ & \\
\hline $61-65$ & $1.2 \pm 0.4$ & & $1.0 \pm 0.0$ & \\
\hline \multicolumn{2}{|l|}{ Gender } & \multirow{3}{*}{0.325} & & \multirow{3}{*}{0.138} \\
\hline Male & $1.2 \pm 0.3$ & & $1.3 \pm 0.4$ & \\
\hline Female & $1.3 \pm 0.5$ & & $1.2 \pm 0.4$ & \\
\hline \multicolumn{2}{|l|}{ Level of education } & \multirow{6}{*}{0.347} & & \multirow{6}{*}{0.982} \\
\hline High education & $2.0 \pm 0.0$ & & $0.0 \pm 0.0$ & \\
\hline Secondary education & $1.0 \pm 0.0$ & & $0.0 \pm 0.0$ & \\
\hline Primary education & $1.3 \pm 0.7$ & & $1.0 \pm-$ & \\
\hline Read and write & $1.0 \pm 0.0$ & & $1.3 \pm 0.3$ & \\
\hline Illiterate & $1.2 \pm 0.2$ & & $1.4 \pm 0.5$ & \\
\hline \multicolumn{2}{|l|}{ Occupation } & \multirow{4}{*}{0.583} & & \multirow{4}{*}{0.162} \\
\hline Employee & $2.0 \pm-$ & & $0.0 \pm 0.0$ & \\
\hline Farmer & $1.3 \pm 0.5$ & & $1.3 \pm 0.5$ & \\
\hline Machinery work & $1.0 \pm-$ & & $1.8 \pm 0.6$ & \\
\hline
\end{tabular}




\begin{tabular}{|l|c|c|c|c|}
\hline \multirow{2}{*}{ Items } & \multicolumn{3}{|c|}{ Post operative complications } \\
\cline { 2 - 5 } & \multicolumn{2}{|c|}{ Control group(n=30) } & \multicolumn{2}{|c|}{ Study group(n=30) } \\
\cline { 2 - 5 } & Mean \pm SD & P-value & Mean \pm SD & P-value \\
\hline House wife & $1.2 \pm 0.4$ & & $1.2 \pm 0.4$ & \\
\hline Not work & $1.0 \pm-$ & & $0.0 \pm 0.0$ & \\
\hline
\end{tabular}

Table (6): Relationship between the studied groups' knowledge about cataract and Post-operative complications.

\begin{tabular}{|c|c|c|c|c|c|}
\hline \multirow{3}{*}{ Knowledge } & \multicolumn{4}{|c|}{ Post-operative complications } & \multirow{3}{*}{$\begin{array}{c}\text { P-value } \\
\text { Between studied groups }\end{array}$} \\
\hline & \multicolumn{2}{|c|}{ Control group } & \multicolumn{2}{|c|}{ Study group } & \\
\hline & F-test & P-value & F-test & P-value & \\
\hline Pre & 2.247 & $0.061 *$ & 0.784 & 0.264 & $0.021 *$ \\
\hline Post & 2.247 & $0.061 *$ & 0.795 & 0.253 & $0.038 *$ \\
\hline
\end{tabular}

On-way-ANOVA test

$*$ Statistical significant differences $(p<0.05)$

Table (7): Relationship between post operative complications and follow up complications for study group regarding to level of knowledge.

\begin{tabular}{|l|c|c|c|c|c|c|}
\hline \multirow{2}{*}{ Knowledge level } & \multicolumn{5}{|c|}{ Complications } \\
\cline { 2 - 3 } & \multicolumn{2}{|c|}{ Post operative complications } & \multirow{2}{*}{ P-value } & \multicolumn{2}{|c|}{ Follow up complications } & \multirow{2}{*}{ P-value } \\
\cline { 2 - 3 } & No & $\%$ & & No & $\%$ & \\
\hline Good level & 26 & 86.7 & \multirow{2}{*}{0.130} & 26 & 86.7 & \multirow{2}{*}{$0.037 *$} \\
\hline Poor level & 4 & 13.3 & & 4 & 13.3 & \\
\hline
\end{tabular}

Statistical significant differences $(p<0.05)$

Table (1): Distribution of studied sample (both control and study groups) as regarding to their sociodemographic characteristics.

This table illustrates that, the highest percentage of both the study and control group were between the ages $41-60$ years old $(43.3 \%$ and $60.0 \%)$ respectively. Also there was a predominance of female in both the study and the control groups $(60.0 \%$ and $66.7 \%)$ respectively. As regarding level of education in both study and control groups the highest percentage were illiterate $(73.4 \%$ and $33.3 \%)$ respectively. Looking at the occupation in both the study and control groups the highest percentage was house wife $(56.7 \%$ and $63.3 \%$ respectively. There were Statistical significant differences between study and control groups as regarding level of education

Table (2): Distribution of studied sample (both control and study groups) as regarding to their medical data.

This table shows that; there was statistical difference between two groups as regarding to medical data in (duration of cataract \&risk factors).

Table (3): Distribution of Patients' knowledge (both control \& study groups) about cataract (pre \&post) application of nursing guidelines.

This table demonstrates that, there was significant statistical difference between pre and post application of guidelines for the study group.
Table (4): Comparison between the control and study groups regarding to post operative complications of cataract surgery

This table clarifies that, the majority of both (control and study groups) had raised intraocular pressure. There was statistical significance between (control and study groups) as regarding raised intraocular pressure.

Table (5): Relationship between patients' post operative complications and socio-demographic characteristics

This table mentions that, there was significant difference between post-operative complications and age of the two groups (control and study).

Table (6): Relationship between the studied groups' knowledge about cataract and Post-operative complications

This table illustrated that; there was statistical significant difference between studied groups as regard their post-operative complications

Table (7): Relationship between post operative complications and follow up complications for study group regarding to level of knowledge

This table shows that; there was statistical significant difference between complications at follow up and knowledge level 


\section{Discussion}

The present study showed that, the highest percentage of both the study and control group were between the ages 41-60 years old. Also there was a predominance of female in both the study and the control groups. This result disagrees with these result by Mohammed et al., (2012) that was carried out in Aga Khan University Hospital, a tertiary care hospital, in Karachi, Pakistan (from August 2010 to July 2011) which revealed that 53 patients were enrolled, $30(56.6 \%)$ of them were male and 23 $(43.4 \%)$ were female. and the result supported by Olawoye et al., (2011) on 184 patients in the University College Hospital Ibadan, Nigeria, which revealed that, there were (100 males $54.3 \%)$ and 84 females $(45.7 \%)$.As regarding level of education in the present study in both study and control groups, the highest percentage were illiterate $(73.4 \%$ and $33.3 \%$ ) respectively.

The present study showed that, more half of patients in the study groups had chronic disease (53.3\%), diabetes mellitus (40\%), and hypertension (13.3\%). There was statistical difference between the two groups as regard to medical data (in duration of cataract, chronic disease and family history). This result agreed with Timby \& Smith, (2013) who stated that a high incidence of cataracts occurs among people with diabetes and those with a family history. In this aspect (Henderson, 2007) mentioned that some patients have a strong family history of cataract that can explain early onset cataract formation.

The current study results revealed that, there was highly statistical difference between (pre and post) applications of guideline, agree with Thomas, (2012) found that there was highly significant between preknowledge and post-knowledge. As well as (Mohamed et al., 2012) mentioned that, there were highly statistically significant difference between pre/post nursing guidelines implementation for study group.

As regarding of complication; there was statistical difference between (control and study) groups in post operative complications of cataract surgery as in control group there are one Eye bruising (3.3\%), three Corneal edema (10\%), one Wound leak(3.3\%), While in study group there are one Eye bruising(3.3\%), two Corneal edema (6.6\%), three Intraocular pressure (10\%).This agree with (Abid Naseem et al., (2007) who reported that, Postoperative complications, Corneal edema 14 (43.8\%), Raised intraocular pressure 5 (15.6\%), and (3.1\%), endophthalmitis $1(3.1 \%)$. This agree with Garima et al., ( 2014) who reported that, immediate postoperative complications raised intraocular pressure, corneal edema and endophthalmitis, there was statistical significance between (control and study groups) groups regarding to complications of cataract surgery at time of follow up.

This study showed that, there was statistical significant difference between studied groups as regard their post-operative complications. This result supported by (Lewis, et al., 2013) who reported that patients knowledge is important because the patient has the right to know and to be informed about diagnoses, treatment, support, and reassurance about the surgical and postoperative experience to reduce or alleviate anxiety. And the patient receives verbal and written instruction regarding how to protect the eye, administer medications, recognize signs of complications, and obtain emergency care. Be available to give the patient and the family information to help them to minimize complications. The results of the present study revealed that, all patients in both groups (control and study) had poor level of knowledge about cataract surgery at the time of admission. Another possible explanation by (Thomas, 2012) who mentioned that knowledge regarding cataract after the structured teaching programme, $47(78 \%)$ cataract patients had adequate knowledge and, $13(22 \%)$. of Cataract patients had moderately adequate knowledge; there is no inadequate knowledge in study group.

\section{Conclusion}

The results of the present study concluded that, the level of knowledge of the study group patients after application of nursing guidelines was higher than the level of knowledge of control group patients who didn't receive the nursing guidelines. Most of the study group patients had minimal post operative complications after application of nursing guidelines than control group.

\section{Recommendations}

Based on the results of the present study, the following can be recommended:

1. Increase patient's awareness about the importance of periodic checks up to prevent developing any complications which can affect on the quality of life.

2. Providing a written instruction booklet is of great important for the patients before discharge to minimize postoperative complications

3. Establishment of continuous health education program at ophthalmology department to provide health teaching using booklet and illustrated pamphlets for each patient

4. It is recommended that similar studies should be replicated on longitudinal bases till one year as a minimum time period for follow up. 


\section{References}

1. Abid Naseem S. , Muhammad N., \& Shad M., (2007): Cataract Surgery in Patients with Pseudoexfoliation . Pakistan Journal of ophthalmology, Vol. 23, p155:160.

2. Anil K., (2013): Lasers and Optoelectronics: Fundamentals, Devices and Applications.ch 12, Laser in Medicine, John Wiley \& Sons, P. 432.

3. Garima R., Shingal P., Vinit, \& Shazia Z., (2014): A Comparative Study of Outcome of Small Incision Cataract Surgery in Eyes with and without Pseudoexfoliation Syndrome, nternational Journal of Scientific Study, September 2014, , Vol.2., No.6, p.78:81

4. Henderson B., (2007): Essentials of Cataract Surgery, Ch1cataract Surgery: Preoperative Evaluation, SLACK Incorporated, p.13.

5. Keith H., Rosenfield M., \& Logan N., (2009): Optometry: Science, Techniques and Clinical Management.Ch 10, Ocular Disease, Elsevier Health Sciences, p. 137.

6. Lewis L., Dirksen S. R., Heitkemper M., \& Bucher L., (2013): Medical-Surgical Nursing: Assessment and Management of Clinical Problems. 9th ed .ch22, Visual and Auditory Problems, Elsevier, Canada, P.393:395.

7. Mohamed H., Frahat N., Meegalla N., \& Abd Elhaleem M., (2012): Nursing Guidelines on Hair Dandruff Symptoms for adult patients. Life Science Journal 2014 Vol. 11, No.1, p.323:333.

8. Muma R., \& Lyons, B., (2011): Patient Education: A Practical Approach. 3rd ed, ch7, Eye, Ear, Nose and Throat, Jones \& Bartlett Publishers, p.57.

9. Olver J., \& Cassidy L., (2009): Ophthalmology at a Glance. Ch3, Cataract Surgery, John Wiley \& Sons India, P.74.

10. Pudner R., (2010): Nursing the Surgical Patient. 3rd ed, Ch11, Patients requiring ophthalmic surgery, Elsevier Health Sciences China, p.132.

11. Rosalin S., Agnes L., \& Mary E., (2013):Ophthalmic Nursing 4th ed. Ch 3,Opthalmic nursing Procedures Ch5, Globe: A Brief Overview Ch 12, The Crystalline Lens Ch 13, Retina, Optic nerve and Vitreous,p.55, John Wiley \& Sons, p.43, p. 205, p.246.

12. Soosan J., Amar A., \& Athiya A., (2012): Phacomulsification. 4th ed, Ch 1, Cataract Etiology, Ch19, Divide and Conquer Nucleofractis Techniques, JP Medical Ltd, p. 3:6, P.176.

13. Stannard D. and Krenzischek D., (2012): PeriAnesthesia Nursing Care.ch31, ophthalmic surgery, Jones \& Bartlett Publishers, p.276

14. Thomas S., (2012): A Study to Evaluate the
Effectiveness of the structured teaching program me on Cataract and Eye care, in terms of knowledge and practice among patients those have undergoing Cataract Surgery in Retina Institute of Karnataka, Bengaluru, Indian Streams Research Journal, Vol. 2,p.1.

15. Timby K., \& Smith E., (2013): Introductory Medical-Surgical Nursing.11th ed Ch41, Caring for Clients with Sensory Disorders, Lippincott Williams \& Wilkins, P.678.

16. Watkinson S., (2009): Issues In Ophthalmic Practice: Current and Future Challenges.ch2, Pre-assessment of day-case cataract surgery, M\&K Update Ltd, p.25.

17. Williams L., \& Hopper P., (2012): Understanding Medical Surgical Nursing.4th ed, ch14, Understanding the sensory system, F.A. Davis United states of America, p.1264. 